\title{
Outcomes of Resident-Performed Descemet's Stripping Automated Endothelial Keratoplasty
}

\author{
Tatyana R. Beketova, BS ${ }^{1}$ Margaret L. Pfeiffer, MD ${ }^{1,2,3}$ Alice Z. Chuang, PhD ${ }^{1} \quad$ Gene Kim, MD ${ }^{1,2,3}$ \\ ${ }^{1}$ Ruiz Department of Ophthalmology and Visual Science, McGovern \\ Medical School at The University of Texas Health Science Center at \\ Houston, Houston, Texas \\ 2 Robert Cizik Eye Clinic, Houston, Texas \\ Address for correspondence Gene Kim, MD, Robert Cizik Eye Clinic, \\ 6400 Fannin Street, Suite 1800, Houston, TX 77030 \\ (e-mail: gene.kim@uth.tmc.edu).
}

${ }^{3}$ Harris Health System, Houston, Texas

Journal of Academic Ophthalmology 2017;9:e26-e31.

\begin{abstract}
Purpose This article aimed to evaluate outcomes of resident-performed Descemet's stripping automated endothelial keratoplasty (DSAEK).

Methods This is a case series of patients who underwent DSAEK performed by PGY-4 ophthalmology residents at Lyndon B. Johnson Hospital from January 2013 to August 2016 staffed by a fellowship-trained cornea specialist. Patients with less than 1 month of follow-up were excluded. Demographics, baseline ocular characteristics, and intraoperative data were recorded. Vision and graft status were recorded at 1 week, 1 month, 3 months, and the last follow-up visits. Surgical failure was defined as graft detachment within 1 week of surgery and/or primary graft failure within 3 months of surgery.

Results Eighteen eyes of 18 patients who followed up for 14.9 months $( \pm 12.9)$ were included. Mean age of patients was 60.9 years $( \pm 13.2)$. Indications for DSAEK included pseudophakic bullous keratopathy (10), Fuchs endothelial dystrophy (4), and other causes of endothelial dysfunction (4). Eleven (61\%) eyes had prior ocular surgery, and 7 (39\%) had prior glaucoma surgery. There were no postoperative graft detachments and two $(11 \%)$ primary graft failures. There was one primary graft failure in a glaucoma patient. Of the 16 graft successes, logMAR visual acuity improved by $0.46 \log M A R$

Keywords

- cornea

- resident

- DSAEK

$( \pm 0.73)$ from baseline.

Conclusion With appropriate staffing by an experienced cornea surgeon, DSAEK with residents as the primary surgeons is a safe and effective procedure with reasonably good outcomes.
\end{abstract}

Descemet's stripping automated endothelial keratoplasty (DSAEK) has replaced penetrating keratoplasty (PKP) as the most common form of corneal transplantation, particularly in cases of corneal endothelial dysfunction. ${ }^{1-3}$ The benefits of DSAEK over PKP include increased speed of visual recovery and decreased graft rejection rate and surgical morbidity. ${ }^{1-4}$ The two major disease processes requiring DSAEK are Fuchs corneal dystrophy and iatrogenic damage.
Iatrogenic damage, also known as pseudophakic bullous keratopathy (PBK), most commonly results from cataract surgery. Endothelial dysfunction can also occur from implant-induced damage-including glaucoma tubes shunts and anterior chamber intraocular lenses (ACIOL). ${ }^{1-4}$

While DSAEK has benefits to the patient, surgeon transition from PKP to DSAEK technique has proven to be technically difficult with a steep learning curve. ${ }^{5-7}$ Many studies received

June 21, 2017

accepted

November 7, 2017
DOI https://doi.org/

10.1055/s-0037-1609035. ISSN $2475-4757$.
Copyright $\odot 2017$ by Thieme Medical

Publishers, Inc., 333 Seventh Avenue, New York, NY 10001, USA. Tel: +1(212) 584-4662.
License terms

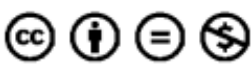


have shown a large improvement in surgical outcomes with an increase in the number of procedures a surgeon has performed, with an improvement even after the first five cases. ${ }^{8}$ Due to the steep learning curve, residents are normally not the primary surgeons for DSAEK, as they will not obtain a satisfactory number of procedures to become proficient during residency. However, the complications of DSAEK surgery when performed by residents as primary surgeons have not been evaluated.

In this study, we retrospectively reviewed the outcomes of DSAEK corneal transplants completed by residents as primary surgeons at the Lyndon B. Johnson Hospital staffed by a fellowship-trained corneal specialist.

\section{Methods}

This retrospective chart review was conducted at the Lyndon B. Johnson Hospital of the Harris Health System, Houston, Texas, United States. Institutional review board approval was obtained from the University of Texas Health Science Center Committee for the Protection of Human Subjects and the Harris Health System. All research adhered to the tenets of the Declaration of Helsinki and was HIPAA compliant.

Charts of all patients who underwent DSAEK for endothelial dysfunction performed by resident surgeons and staffed by a fellowship-trained cornea specialist from January 2013 to September 2016 were reviewed. Patients with less than 1 month of follow-up were excluded. Demographics (race, sex, age) and ocular surgical history were recorded. Preoperative data collected were best-corrected or pinhole distance visual acuity (VA) and indications for DSAEK (PBK, Fuchs endothelial dystrophy [Fuchs], or other corneal endothelial pathology [others]). Intraoperative data collected were concurrent procedures performed, surgical parameters, and intraoperative complications. Postoperative data collected were presence of graft detachment at week 1; graft failure (as determined by slit lamp examination by a cornea specialist) at week 1 , month 1 , month 3 , and at last follow-up; and VA at last follow-up.

\section{Surgical Technique}

Surgeries were conducted under monitored anesthesia care with a retrobulbar block or general anesthesia based on participants' health and planned concurrent surgeries. All concurrent surgical procedures (phacoemulsification with intraocular lens [IOL] placement, removal or revision of anterior chamber tube shunt [ACTS], etc.) were performed just prior to DSAEK. All donor corneas were from the Lions Eye Bank at Baylor College of Medicine, Houston, Texas, United States. All had endothelial cell counts greater than 2,300 cells $/ \mathrm{mm}^{2}$.

Superior, inferior, and nasal $1.0-\mathrm{mm}$ paracenteses were made at the corneal limbus. The eye was filled with a cohesive viscoelastic, and the potential cornea donor size was determined using calipers. Depending on the measurement, a trephine of appropriate size-ranging from 6.5 to $9.0 \mathrm{~mm}-$ was determined by the attending surgeon and was used to mark the graft on the cornea. A clear corneal incision was made temporally in a triplanar fashion with a keratome to a width of 3.5 to $4.5 \mathrm{~mm}$, except in cases that involved removal of an ACIOL, where a $6.5-\mathrm{mm}$ superior scleral tunnel was made. For the Fuchs dystrophy participants, Descemet's membrane was removed using a reverse Sinskey hook. Earlier cases had 4 1.0$\mathrm{mm}$ venting incisions placed tangential and slightly central to the trephination marks on the host cornea. Viscoelastic was removed with bimanual irrigation and aspiration. For the PBK patients and patients with previous incisional glaucoma surgery, the eye was not inflated with viscoelastic, and the Descemet's membrane was not stripped.

All corneal tissue was pre-cut by the eye bank, and a donor punch was used to cut the corneal graft after the anterior stroma was removed. A 20-gauge Lewicky anterior chamber maintainer was placed in the inferior paracentesis. The graft was transferred endothelial side up into a Busin glide and advanced forward using 25-gauge internal limiting membrane (ILM) forceps. There was no viscoelastic placed on the DSAEK graft. The 25-gauge ILM forceps were then placed through the nasal paracentesis, out the main temporal wound, and used to pull the DSAEK lenticule into the anterior chamber endothelial side down. The Lewicky anterior chamber maintainer was then removed, and the temporal wound was closed with 10-0 nylon sutures in an interrupted fashion. The entire anterior chamber was filled with filtered air, and the lenticule was inspected for centration and repositioned externally with a flap roller or, if necessary, internally with a reverse Sinskey hook.

An antibiotic/steroid ointment was applied to the ocular surface, and a patch and shield were placed over the operative eye. All participants remained in the postanesthesia care unit for 1 hour in a face-up position after surgery. All participants who did not have prior glaucoma surgery were taken to the slit lamp to remove $50 \%$ of the air bubble prior to discharge home to prevent pupillary block. If a participant had a prior incisional glaucoma surgery, the participant was sent home after spending 1 hour in a faceup position without any removal of the air bubble. All participants were instructed to remain in a face-up position at home for 3 days after the procedure.

\section{Outcome Measures}

The primary outcome was surgical failure and defined as the presence of graft detachment at postoperative week 1 or graft failure at or before postoperative month 3. Graft detachment was defined as less than $90 \%$ adherence between the donor graft and the host posterior corneal stroma or any lenticule that required secondary surgical intervention (rebubbling or regraft). ${ }^{9}$ Primary graft failure was defined by any corneal edema over the graft by slit lamp examination. ${ }^{10}$ Secondary outcomes were intraoperative complications and change in VA from baseline to last follow-up.

\section{Data Analysis}

Data were summarized by mean ( \pm standard deviation) or by frequency (\%). All statistical analyses were performed using SAS v9.4 for Windows (SAS Institute, Inc., Cary, North Carolina, United States). 
Table 1 Summary of demographics and baseline ocular characteristics

\begin{tabular}{|c|c|}
\hline Variable & $\begin{array}{l}\text { All eyes } \\
(N=18)\end{array}$ \\
\hline Eye (right, \%) & $12(67 \%)$ \\
\hline Age (y, \pm SD, [range]) & $\begin{array}{l}60.9( \pm 13.2) \\
{[23-80]}\end{array}$ \\
\hline Sex (males, \%) & 7 (39\%) \\
\hline \multicolumn{2}{|l|}{ Race (\%) } \\
\hline White & $4(22 \%)$ \\
\hline Black & $3(17 \%)$ \\
\hline Hispanic & $9(50 \%)$ \\
\hline Asian & $2(11 \%)$ \\
\hline \multicolumn{2}{|l|}{ Indication for DSAEK (\%) } \\
\hline Pseudophakic bullous keratopathy & $10(56 \%)$ \\
\hline Fuchs endothelial dystrophy & $4(22 \%)$ \\
\hline Others & $4(22 \%)$ \\
\hline $\begin{array}{l}\text { Previous complex } \\
\text { ocular surgery }(n, \%)\end{array}$ & $11(61 \%)$ \\
\hline Previous glaucoma surgery $(n, \%)$ & 7 (39\%) \\
\hline $\begin{array}{l}\text { Baseline visual acuity } \\
\text { (logMAR, } \pm \text { SD, [range]) }\end{array}$ & $\begin{array}{l}1.33( \pm 0.84) \\
{[0.1-2.7]}\end{array}$ \\
\hline $\begin{array}{l}\text { Duration of follow-up period } \\
\text { (mo, } \pm \text { SD, [range]) }\end{array}$ & $\begin{array}{l}14.9( \pm 12.9) \\
{[1.7-43.2]}\end{array}$ \\
\hline
\end{tabular}

Abbreviations: DSAEK, Descemet's stripping automated endothelial keratoplasty; SD, standard deviation.

${ }^{a}$ Excludes uneventful phacoemulsification with intraocular lens.

\section{Results}

\section{Demographics and Baseline Ocular Characteristics}

Twenty eyes of 19 patients who underwent DSAEK during the study period were reviewed. Two eyes were excluded due to less than 1 month of follow-up. Eighteen eyes of 18 participants were included. The mean age was $60.9 \pm 13.2$ years. Seven (39\%) participants were male. Nine (50\%) participants were Hispanic, four $(22 \%)$ were white, three $(17 \%)$ were black, and two (11\%) were Asian. Indications for DSAEK included 10 (56\%) PBK, 4 (22\%) Fuchs, and 4 (22\%) others. Others included herpetic endothelial dysfunction, iridocorneal endothelial syndrome (ICE), and implant-induced endothelial failure from ACTS. Eleven (61\%) study eyes had complex ocular surgical histories with at least one previous ocular surgery (excluding uneventful phacoemulsification with IOL placement). Of these 11 eyes, 7 eyes had prior glaucoma surgery. Demographics and baseline ocular characteristics are summarized in -Table $\mathbf{1}$.

\section{Surgical Procedures}

Surgeries were performed by 10 PGY-4 residents. Each resident performed an average of two DSAEKs (range: 1-3). Nine eyes had DSAEK alone, and the remaining 9 eyes had DSAEK with another procedure. Descemet's membrane was not
Table 2 Summary of surgical procedures performed

\begin{tabular}{|l|l|}
\hline Variable & \multicolumn{1}{|l|}{$\begin{array}{l}\text { All eyes } \\
(N=18)\end{array}$} \\
\hline Combined procedure (\%) & $9(50 \%)$ \\
\hline None & $4(22 \%)$ \\
\hline Phacoemulsification/IOL & $2(11 \%)$ \\
\hline Revision of ACTS & $3(17 \%)$ \\
\hline Scleral-sutured IOL $+/-$ ACIOL removal & $10(56 \%)$ \\
\hline Venting incision used $(n, \%)$ & $11(61 \%)$ \\
\hline Descemet's not stripped $(n, \%)$ &
\end{tabular}

Abbreviations: ACIOL, anterior chamber intraocular lens; ACTS, anterior chamber tube shunt; IOL, intraocular lens.

stripped for all PBK patients, except for two early cases, and for two patients with previous incisional glaucoma surgery. Venting incisions were done in five PBK patients and one patient with previous incisional glaucoma surgery. Overall, 10 eyes had venting incisions, and 7 eyes had Descemet's membrane stripped (-Table 2 ). The stromal bed was not scraped, and peripheral iridotomies were not made on any eyes.

\section{Outcomes}

\section{Surgical Outcomes}

There were no graft detachments ( 0 eyes, $0 \%$ ) at the 1 -week postoperative visit. Two eyes (11\%; $95 \%$ confidence interval $[\mathrm{CI}]=[0 \%, 26 \%])$ developed primary graft failure, characterized by endothelial irregularities and irreversible edema, resulting in graft replacement with PKP. One of 11 eyes (9\%) with prior complex ocular surgery (excluding uneventful phacoemulsification) and 1 of 7 eyes (14\%) with prior glaucoma surgery were surgical failures ( - Tables 3 and $\mathbf{4}$ ).

One eye that developed primary graft failure underwent DSAEK surgery for PBK. This eye had an extensive ocular surgical history prior to the DSAEK: ACTS, phacoemulsification with IOL placement in the capsular bag, three ACTS revisions with repositioning, and a pars plana vitrectomy. At postoperative week 1 , the graft was fully attached yet opaque and edematous. At postoperative month 3, there was iridocorneal touch superiorly and bullous keratopathy.

The other eye that developed primary graft failure underwent a combined DSAEK with phacoemulsification with IOL placement for bullous keratopathy from ICE. An anterior capsule was torn intraoperatively during phacoemulsification, requiring the placement of a sulcus IOL. At postoperative week 1 , the graft was attached centrally; however, the cornea was edematous with stromal haze, microcystic edema, and an epithelial defect at and after the month 1 visit. This patient had no prior ocular surgeries.

\section{Functional Outcomes}

At the last follow-up visit, the average VA of all 18 eyes was 0.99 $\log$ MAR $( \pm 0.87$ ), which was an improvement of $0.34 \log$ MAR $( \pm 0.83)$ from the baseline vision. Of the 16 surgical successes, the average VA at the last visit $(0.91 \log$ MAR $[ \pm 0.80])$ was 
Table 3 Summary of surgical outcomes for baseline characteristics and surgical parameters

\begin{tabular}{|c|c|c|c|c|}
\hline \multirow[t]{2}{*}{ Variable } & \multirow{2}{*}{$\begin{array}{l}\text { All Eyes } \\
(N=18) \\
\left(n, \%^{a}\right)\end{array}$} & \multicolumn{2}{|c|}{ Surgical failure eyes $(N=2)$} & \multirow{2}{*}{$\begin{array}{l}\text { Surgical success eyes } \\
(N=16) \\
\left(n, \%^{\mathrm{b}}\right)\end{array}$} \\
\hline & & $\begin{array}{l}\text { Graft detachment } \\
(N=0)\end{array}$ & $\begin{array}{l}\text { Graft failure } \\
(N=2) \\
\left(n, \%^{b}\right)\end{array}$ & \\
\hline Previous complex ocular surgeryc & $11(61 \%)$ & 0 & $1(9 \%)$ & $10(91 \%)$ \\
\hline Previous glaucoma surgery & 7 (39\%) & 0 & $1(14 \%)$ & $6(86 \%)$ \\
\hline \multicolumn{5}{|l|}{ Indication for DSAEK } \\
\hline Pseudophakic bullous keratopathy & $10(56 \%)$ & 0 & $1(1 \%)$ & $9(90 \%)$ \\
\hline Fuchs endothelial dystrophy & $4(22 \%)$ & 0 & $0(0 \%)$ & $4(100 \%)$ \\
\hline Others & $4(22 \%)$ & 0 & $1(50 \%)$ & $3(75 \%)$ \\
\hline Venting incision used & $10(56 \%)$ & 0 & $1(10 \%)$ & $9(90 \%)$ \\
\hline \multicolumn{5}{|l|}{ Descemet's stripped } \\
\hline Yes & 7 (39\%) & 0 & $1(14 \%)$ & $6(86 \%)$ \\
\hline No & $11(61 \%)$ & 0 & $1(9 \%)$ & $10(91 \%)$ \\
\hline Intraoperative complications & $1(6 \%)$ & 0 & $1(100 \%)$ & $0(0 \%)$ \\
\hline
\end{tabular}

Abbreviations: DSAEK, Descemet's stripping automated endothelial keratoplasty; IOL, intraocular lens.

apercentages among all eyes.

bercentages among eyes with that baseline characteristic or surgical parameter.

'Excludes uneventful phacoemulsification with IOL.

Table 4 Summary of surgical outcomes in patients with previous complex ocular surgeries ${ }^{\text {a }}$

\begin{tabular}{|c|c|c|c|c|c|c|}
\hline ID & Prior complex ocular surgeries ${ }^{a}$ & $\begin{array}{l}\text { No. of prior } \\
\text { complex } \\
\text { ocular } \\
\text { surgeries }\end{array}$ & $\begin{array}{l}\text { Indication } \\
\text { for DSAEK }\end{array}$ & Type of surgery & $\begin{array}{l}\text { Graft } \\
\text { detachment }\end{array}$ & $\begin{array}{l}\text { Graft } \\
\text { failure }\end{array}$ \\
\hline 1 & ACTS; ACTS repositioning to sulcus & 2 & Others & DSAEK & No & No \\
\hline 2 & Phaco/IOL; ACTS & 2 & PBK & DSAEK/ACTS trimming & No & No \\
\hline 3 & $\begin{array}{l}\text { Phaco/ACIOL; PPV with removal of } \\
\text { retained lens material; } \\
\text { ACIOL explantation; ACTS }\end{array}$ & 4 & PBK & DSAEK/sutured IOL & No & No \\
\hline 4 & $\begin{array}{l}\text { Scleral buckle; secondary } \\
\text { IOL; IOL exchange }\end{array}$ & 3 & PBK & DSAEK & No & No \\
\hline 5 & $\begin{array}{l}\text { ACTS; phaco/IOL; ACTS } \\
\text { revision/reposition } \times 3 \text { with PPV }\end{array}$ & 5 & PBK & DSAEK & No & Yes \\
\hline 6 & Trabeculectomy; phaco/IOL & 2 & PBK & DSAEK & No & No \\
\hline 7 & $\begin{array}{l}\text { ACTS; revision of ACTS; } \\
\text { phaco/sulcus IOL; } \\
\text { additional ACTS }\end{array}$ & 4 & Others & $\begin{array}{l}\text { DSAEK/reposition } \\
\text { of ACTS }\end{array}$ & No & No \\
\hline 8 & $\begin{array}{l}\text { Scleral buckle; phaco/sulcus IOL; } \\
\text { PPV/removal of sulcus IOL and } \\
\text { retained lens fragments }\end{array}$ & 3 & PBK & DSAEK/sutured IOL & No & No \\
\hline 9 & Phaco/aphakic; PPV/scleral-sutured IOL & 2 & PBK & DSAEK & No & No \\
\hline 10 & Phaco/ACIOL & 1 & PBK & DSAEK & No & No \\
\hline 11 & ACTS; phaco/ACIOL & 2 & PBK & $\begin{array}{l}\text { DSAEK/ACIOL } \\
\text { removal/sutured IOL }\end{array}$ & No & No \\
\hline
\end{tabular}

Abbreviations: ACIOL, anterior chamber intraocular lens; ACTS, anterior chamber tube shunt; DSAEK, Descemet's stripping automated endothelial keratoplasty; IOL, intraocular lens; Phaco, phacoemulsification; PPV, pars plana vitrectomy.

Forward slash (/) indicates procedures performed during single operation; semicolons separate different operations.

aExcludes uncomplicated phacoemulsification with IOL. 
significantly improved by $0.46 \log \mathrm{MAR}( \pm 0.73)$ from baseline $(1.37 \log$ MAR $[ \pm 0.89])(p=0.024)$. The mean improvement in VA from baseline was similar among the three indications, 0.47 $\operatorname{logMAR}( \pm 0.62)$ for Fuchs, $0.15 \operatorname{logMAR}( \pm 1.01)$ for PBK, and $0.68 \log \mathrm{MAR}( \pm 0.62)$ for others $(p=0.58)$.

\section{Discussion}

DSAEK offers improved visual outcomes and has a more favorable complication profile in comparison to PKP; however, DSAEK requires greater surgical skill and is traditionally reserved for cornea fellows and attending physicians. ${ }^{1,2,4}$ This study showed that no eyes $(0 \%)$ developed graft detachment and two eyes (11\%) developed primary graft failure when DSAEK was performed by residents as the primary surgeons.

The learning curve for DSAEK surgery is a common topic in the literature, and it is widely accepted that the rates of graft detachment and failure improve with surgeon experience. Mojica et al stratified surgeon experience into five levels, with a level 1 surgeon having done 1 to 10 DSAEK surgeries and a level 5 surgeon having done more than 100 DSAEK surgeries. The authors reported a primary graft failure rate of $21.8 \%$ for the level 1 surgeon compared with $1.5 \%$ for the level 5 surgeon. ${ }^{6}$ Hashemi et al reviewed the results of DSAEK surgery for cornea fellows and found graft detachment in 17 eyes $(21.7 \%)$ and graft failure in 8 eyes $(10.2 \%),{ }^{5}$ compared with a graft detachment rate of 2.7 and $8.9 \%$ and a graft failure rate of 4.1 and $3.0 \%$ in attending surgeons at a tertiary academic center in eyes without previous glaucoma surgery. ${ }^{11,12}$ Given this steep learning curve, cornea specialists are hesitant to allow residents to be primary surgeons for DSAEK surgery, and to the best of our knowledge, we could not find any other publications in the literature discussing the results of residents as primary surgeons for DSAEK (PubMed search on May 14, 2017, using the terms "DSAEK" and "resident," or "DSAEK" and "novice"). The only study that touches on resident outcomes for DSAEK involved ex vivo cadaveric eyes, and this study also showed that endothelial cell loss improved with surgical experience. ${ }^{8}$

All of these DSAEK surgical cases were staffed by a single experienced cornea-fellowship-trained attending who would be a level 5 surgeon ( $>100$ cases) in experience as defined by Mojica et al. ${ }^{6}$ It seems logical that the level of experience of the attending surgeon may be a more important factor than the level of experience of the resident surgeon, as surgical decision making is as important as technical skill level in performing a successful DSAEK surgery.

In our study, 10 different PGY-4 residents served as primary surgeons, and no single resident had done more than three cases. Our graft detachment rate of $0 \%$ and primary graft failure rate of $11 \%$ are far better than those discussed in the literature for novice surgeons. ${ }^{5,6}$ There are several technique variations that, we think, make our procedure easier for novice surgeons: (1) use of a Busin glide; (2) use of an anterior chamber maintainer; (3) no viscoelastic on graft; and (4) no stripping of Descemet's membrane for PBK and glaucoma incisional surgery patients. Given that most of the studies of the results of novice surgeons used a forceps delivery for graft placement, this study may indicate that a Busin glide delivery may be an easier surgical technique for the novice surgeon. ${ }^{13,14}$ The anterior chamber maintainer prevents shallowing, particularly in cases with an ACTS; allows graft insertion above the tube; and avoids mechanical trauma to the graft from the tube. The anterior chamber maintainer also does not require viscoelastic on the graft, which can deposit in the interface and cause early graft detachment.

There is a precedent to our surgical technique to explain not stripping Descemet's membrane in glaucoma surgery patients. Fuchs dystrophy is a disease of the Descemet's membrane, as evidenced by thickening of Descemet's membrane and formation of guttate on histopathology, and Descemet's membrane needs to be removed prior to DSAEK surgery. ${ }^{15}$ There have been reports that by merely removing Descemet's membrane, peripheral endothelial cells will migrate centrally and result in corneal clearing even without the insertion of a DSAEK lenticule. ${ }^{16}$ PBK and endothelial dysfunction related to glaucoma and glaucoma surgery, however, are iatrogenic and involve only endothelial cell loss without any disease of Descemet's membrane. Not removing the Descemet's membrane makes the surgery technically easier and allows the surgery to be free of any viscoelastic agent, which may also contribute to early postoperative graft detachment. A variety of different DSAEK techniques have been used with variations in wound size and the presence or absence of venting incisions, ${ }^{7,14,17-20}$ with none of these technique variations yielding a superior outcome. Of note, none of the eyes had the host stromal bed scraped as described by Terry et al. ${ }^{19}$

Many of these patients were not ideal candidates for a novice DSAEK surgeon, as many of the patients had concurrent surgery involving tube revision, ACIOL removal, scleral-sutured IOL, and previous glaucoma surgery (-Table 4). The results from our resident surgeons are much better than those published even for attending surgeons. Our results in glaucoma surgical patients yielded a $0 \%$ detachment rate and a $14 \%$ primary failure rate, which is much better than those published in the literature, albeit our study had only seven eyes with these characteristics. Prior glaucoma surgery is known to increase the detachment and primary failure rate even in the hands of the most experienced surgeons. ${ }^{11,12,21-23}$

One reason for the difference in complication rates in our study for eyes with prior glaucoma surgery may be a difference in technique. For eyes with PBK or glaucoma-related (both surgical and nonsurgical) endothelial dysfunction, the Descemet's membrane was not stripped as part of the surgery, which is unique when compared with most of the sentinel DSAEK techniques published. ${ }^{7,14,17-20}$ Another difference lies at the end of the case, where the entire eye was filled with air, and the participant left in a face-up position for 1 hour after the surgery and allowed to go home without air removal. Anecdotally, even with eyes filled with air at the end of surgery, many of these participants would come to their postoperative day 1 visits without any air in the anterior chamber. No participants had an intraocular pressure spike on postoperative day 1. Having a complete air fill prior to discharge may have improved the rate of graft adherence in patients with incisional glaucoma surgery. 
A limitation of this study is that it is a retrospective case series that does not contain a control group; thus, we cannot ascertain which surgical variation changed outcomes. Our primary outcome was determined by slit lamp examination. Future studies should include endothelial cell count and percentage of cell loss; however, because this study was retrospective, these data were not available. In addition, there is a relatively small sample size.

Our study shows the results of 10 resident primary surgeons with minimum to no prior DSAEK surgical experience who achieved a comparable complication rate to those published in the literature. DSAEK surgery with residents as the primary surgeon is a safe and effective procedure with reasonably good outcomes as long as they are staffed by an experienced cornea surgeon.

\section{Conflict of Interest}

Dr. Pfeiffer reports other from Hermann Eye Fund, during the conduct of the study.

Ms. Beketova reports other from Hermann Eye Fund, during the conduct of the study.

Dr. Chuang reports other from Hermann Eye Fund, during the conduct of the study.

Dr. Kim reports other from Hermann Eye Fund, during the conduct of the study.

\section{Acknowledgments}

This study was supported in part by the Hermann Eye Fund.

\section{References}

1 Ang M, Soh Y, Htoon HM, Mehta JS, Tan D. Five-year graft survival comparing Descemet stripping automated endothelial keratoplasty and penetrating keratoplasty. Ophthalmology 2016;123 (08):1646-1652

2 Lee WB, Jacobs DS, Musch DC, Kaufman SC, Reinhart WJ, Shtein RM. Descemet's stripping endothelial keratoplasty: safety and outcomes: a report by the American Academy of Ophthalmology. Ophthalmology 2009;116(09):1818-1830

3 Price MO, Gorovoy M, Benetz BA, et al. Descemet's stripping automated endothelial keratoplasty outcomes compared with penetrating keratoplasty from the Cornea Donor Study. Ophthalmology 2010;117(03):438-444

4 Price MO, Calhoun P, Kollman C, Price FW Jr, Lass JH. Descemet stripping endothelial keratoplasty: ten-year endothelial cell loss compared with penetrating keratoplasty. Ophthalmology 2016;123 (07):1421-1427

5 Hashemi H, Asghari H, Amanzadeh K, Behrooz MJ, Beheshtnejad A, Mohammadpour M. Descemet stripping automated endothelial keratoplasty performed by cornea fellows. Cornea 2012;31 (09):974-977

6 Mojica G, Padnick-Silver L, Macsai MS. Incidence of presumed iatrogenic graft failure in Descemet stripping automated endothelial keratoplasty. Cornea 2012;31(08):872-875

7 Price FW Jr, Price MO. Descemet's stripping with endothelial keratoplasty in 200 eyes: early challenges and techniques to enhance donor adherence. J Cataract Refract Surg 2006;32(03): 411-418

8 Riaz KM, Grewal DS, Cervantes P, Basti S. Endothelial damage with two DSAEK insertion techniques performed by a novice corneal surgeon in residency training: a comparative analysis. Cornea 2014;33(01):91-95

9 Dapena I, Ham L, Droutsas K, van Dijk K, Moutsouris K, Melles GR. Learning curve in Descemet's membrane endothelial keratoplasty: first series of 135 consecutive cases. Ophthalmology 2011;118(11):2147-2154

10 Shih CY, Ritterband DC, Rubino S, et al. Visually significant and nonsignificant complications arising from Descemet stripping automated endothelial keratoplasty. Am J Ophthalmol 2009; 148(06):837-843

11 Decroos FC, Delmonte DW, Chow JH, et al. Increased rates of Descemet's stripping automated endothelial keratoplasty (DSAEK) graft failure and dislocation in glaucomatous eyes with aqueous shunts. J Ophthalmic Vis Res 2012;7(03):203213

12 Kang JJ, Ritterband DC, Lai K, Liebmann JM, Seedor JA. Descemet stripping endothelial keratoplasty in eyes with previous glaucoma surgery. Cornea 2016;35(12):1520-1525

13 Bahar I, Kaiserman I, Sansanayudh W, Levinger E, Rootman DS. Busin guide vs forceps for the insertion of the donor lenticule in Descemet stripping automated endothelial keratoplasty. Am J Ophthalmol 2009;147(02):220-226

14 Busin M, Bhatt PR, Scorcia V. A modified technique for Descemet membrane stripping automated endothelial keratoplasty to minimize endothelial cell loss. Arch Ophthalmol 2008;126 (08):1133-1137

15 Eghrari AO, Riazuddin SA, Gottsch JD. Fuchs corneal dystrophy. Prog Mol Biol Transl Sci 2015;134:79-97

16 Shah RD, Randleman JB, Grossniklaus HE. Spontaneous corneal clearing after Descemet's stripping without endothelial replacement. Ophthalmology 2012;119(02):256-260

17 Gorovoy MS. Descemet-stripping automated endothelial keratoplasty. Cornea 2006;25(08):886-889

18 Mehta JS, Por YM, Beuerman RW, Tan DT. Glide insertion technique for donor cornea lenticule during Descemet's stripping automated endothelial keratoplasty. J Cataract Refract Surg 2007;33(11):1846-1850

19 Terry MA, Shamie N, Chen ES, Hoar KL, Friend DJ. Endothelial keratoplasty a simplified technique to minimize graft dislocation, iatrogenic graft failure, and pupillary block. Ophthalmology 2008;115(07):1179-1186

$20 \mathrm{Wu}$ EI, Ritterband DC, Yu G, Shields RA, Seedor JA. Graft rejection following Descemet stripping automated endothelial keratoplasty: features, risk factors, and outcomes. Am J Ophthalmol 2012;153(05):949-957.e1

21 Goshe JM, Terry MA, Li JY, Straiko MD, Davis-Boozer D. Graft dislocation and hypotony after Descemet's stripping automated endothelial keratoplasty in patients with previous glaucoma surgery. Ophthalmology 2012;119(06):1130-1133

22 Kim P, Amiran MD, Lichtinger A, Yeung SN, Slomovic AR, Rootman DS. Outcomes of Descemet stripping automated endothelial keratoplasty in patients with previous glaucoma drainage device insertion. Cornea 2012;31(02):172-175

23 Nguyen P, Khashabi S, Chopra V, et al. Descemet stripping with automated endothelial keratoplasty: a comparative study of outcome in patients with preexisting glaucoma. Saudi J Ophthalmol 2013;27(02):73-78 